\title{
Relatedness of People's Perceptions and Experiences of Change to the Status of Change: Lessons from the Department of Correctional Services of South Africa
}

\author{
Mbongeni A. Mdletye \\ Jos Coetzee \\ Wilfred I. Ukpere \\ Department of Industrial Psychology and People Management, Faculty of Management \\ University of Johannesburg, Johannesburg, South Africa \\ E-mail: wiukpere@uj.ac.za, mbongeni@telkomsa.net
}

Doi:10.5901/mjss.2014.v5n10p634

\section{Abstract}

This paper follows other papers published by the authors whose focus was on the human dimension of transformational change within an offender correctional environment. Transformational change in Correctional Services represents a paradigm shift in the treatment of offenders from a punishment-based philosophy to a rehabilitation-driven approach. The paper seeks to give an account of the relatedness of people's perceptions and experiences of change to the status of change based on empirical evidence collected from the correctional centres of the Department of Correctional Services in the KwaZulu-Natal Province of the Republic of South Africa. There is currently minimal practical proof and confirmation on the significant role that people issues play in influencing the course of change in terms of whether the change implemented would be successful or not. This gap motivated the authors to undertake an empirical study which investigated and explored the correlation between people's perceptions and experiences of change to the status of change from the perspective of correctional officials and offenders. This was a meaningful and distinctive study given the fact that organisational change scholars have advanced a plausible argument that the high failure rate in transformational change implementation is attributed to the neglect of the human factor during the planning and implementation phases of the change management process. The study was intended to benefit change strategists and change implementers in both service delivery and profit-making organisations in South Africa and globally. For purposes of contextualising the association between people's perceptions and experiences of change and the status of change within the Department of Correctional Services and South Africa in general, an extensive literature study was undertaken. The literature study was followed by the empirical study whereby data was collected by means of two survey questionnaires tailor made for correctional officials and offenders. The empirical findings pointed to the fact that there is indeed a causal link between correctional officials' and offenders' perceptions and experiences of DCS transformational change and the status of DCS transformational change.

Keywords: Change management, Emotional reaction, Experiences, Perceptions, Resistance, Transformational change

\section{Introduction and Background}

Empirical studies conducted by organisational change scholars such as Coetzee and Stanz (2007), Turner, Hallencreutz and Haley (2009), Lotich (2011), and Choi and Ruona (2011) have highlighted that there is a dismal success rate in organisational change implementation. This dismal performance in change implementation is attributed to the neglect of the human factor by change strategists and change implementers at change planning and change implementation levels. The high failure rate coupled with the pointers to the neglect of the human element as the source of the change implementation challenge as well as limited empirical literature has generated a growing interest in conducting more empirical studies, including this one, on the human dimension of organisational change.

Perceptions and experiences have a significant and profound influence on any change process, particularly when it comes to creating resistance to change (Refferty \& Griffin, 2006; Ursiny \& Kay, 2007; Vithessonthi, 2007; Van Tonder, 2006, 2009). When the organisational change effort is perceived as desirable and necessary, people react positively to the change and as such, change is experienced positively and consequently, resistance is lessened. Positive perceptions and experiences of organisational change (personal and organisational) evoke positive emotional reactions that galvanise and mobilise support for change (Van Tonder, 2004a). Therefore, positive perceptions and experiences facilitate implementation of organisational change initiatives. They build the required support for change. For this reason, one may argue that positive perceptions and experiences do contribute to the effective implementation of organisational change efforts. When the organisational change initiative is perceived as undesirable and unnecessary, reacted to and experienced negatively, resistance may escalate to an extent that the change effort collapses and becomes a failure (Macri, Tagliaventi \& Bertolotti, 2002). For this reason, one may posit that negative perceptions and experiences hinder 
success in the implementation of organisational change efforts. Therefore, people's negative perceptions and experiences must be counted amongst factors that are regarded as contributors to ineffective change implementation.

People's perceptions and experiences of change are counted amongst the significant factors that influence the status of organisational change efforts (Walston and Chadwick, 2003). Therefore, change perceptions and experiences may contribute to either the effective facilitation of the change implementation process, thereby leading to change implementation success, or the derailment of change implementation, thereby leading to change implementation failure. George and Jones (2001) and Van Tonder $(2006,2009)$ also emphasise that the manner in which change is perceived and experienced at personal level determines whether change implementation will be successful or not. This view is also vindicated by Decker, Wheeler, Johnson and Parsons (2001) who indicates that the employees' perceptions and experiences play a critical role in the success or failure of any organisational change process. The foregoing assertions underscore the argument that the effective implementation of organisational change initiatives depends inter alia on a thorough understanding of how people as individuals perceive and experience change (Van Tonder, 2004b). Therefore, it can be asserted that perceptions and experiences of change do facilitate or hinder the efficacious implementation of change efforts. This reflects that there a causal link between perceptions and experiences of change and the status of change. For this reason, perceptions and experiences of change play a significant role in determining the status of the change (Refferty \& Griffin, 2006; Ursiny \& Kay, 2007; Vithessonthi, 2007; Van Tonder (2009).

In the light of the above argument, it should be emphasised that change management should also incorporate the understanding of how organisational members perceive and experience change at personal and collective levels, as well as how their perceptions and experiences influence their emotional reactions to the change (Decker, Wheeler, Johnson \& Parsons, 2001; Van Tonder, 2004b; Vakola \& Nikola, 2005). Without a deeper understanding of people's perceptions and experiences of change events being implemented, change implementers will find it difficult to facilitate change implementation effectively. Therefore, one can infer from the foregoing that people's perceptions and experiences of change form part of the critical determinants of effective implementation of change and as such, managers should make meaningful efforts to manage negative perceptions and experiences of change which unfortunately have a profound effect on change implementation in terms of people's support for or opposition to change, which ultimately determines whether the transformational change effort being implemented will be a success or failure. Therefore, it is important to ensure that people's negative perceptions and experiences of change, as well as their negative emotional reactions to change are minimised to the lowest level possible (Zolno, 2009; Panao, 2010). For this reason, it becomes necessary for organisational change researchers to focus more on establishing the causal association between people's perceptions and experiences of change, be they positive or negative, and the status of change.

\subsection{Problem statement}

It is crucial for the Department of Correctional Services' leadership at all levels of the organisational hierarchy to become fully conversant with the causal link between correctional officials' and offenders' perceptions and experiences of the DCS transformational change and the status of the DCS transformational change. This becomes more important when one considers the fact that the new White Paper on Corrections (2005; p15) states that, "every employee of Correctional Services is a rehabilitator". The Department will succeed in implementing this paradigm-altering change effort, including transforming correctional officials into effective rehabilitators of offenders, if and when there is a concerted effort to understand the association between correctional officials' perceptions and experiences of the DCS change and the status of the DCS change. This will assist managers to address correctional officials' concerns and expectations that inform their perceptions and experiences. The failure by managers to acknowledge the profound influence that people's perceptions and experiences have on the status of change, be it positive or negative influence, which is compounded by the limited literature on the subject, reflects the enormity of the challenge confronting change implementers within the domain of transformational change management in both the public and private sector organisations, including the Department of Correctional Services where the empirical study was conducted.

\subsection{Objectives}

The objectives of this paper are:

- To emphasise the importance of managers in establishing, understanding and addressing people's perceptions and experiences during the transformational change implementation process;

- To establish and explore the causal link between people's perceptions and experiences and the status of transformational change within the South African Department of Correctional Services; and

- To highlight the importance of managers in both public and private sector organisations, in addressing, 
through decisive managerial action, the influence of people's negative perceptions and experiences on the status of change such that their influence is minimised and contained.

\subsection{Significance and contributions of the study}

The findings of the study will enhance the existing literature on transformational change management in that they will add more empirical evidence, particularly when it comes to the significance of managing the people issues as part of transformational change management. The outcome of the study will be of enormous value to change agents, change strategists, change implementers, change recipients, organistional development practitioners and managers in general in public and private sector organisations in South Africa, who are charged with the enormous responsibility of initiating, implementing, institutionalising and sustaining transformational change efforts which are part of the government's agenda of reconstructing and developing the South African society within the social, economic, and political arenas. The study's setting within the Department of Correctional Services will enhance and deepen the understanding of Correctional Services' managers at change strategist level, change implementation level, and change recipient level insofar as transformational change management is concerned, particularly when it comes to the effective and efficient facilitation of transformational change at personal level on the part of both correctional officials and offenders.

\section{Literature Review}

Enhancing organisational effectiveness and efficiency requires managers to revamp organisational structures, systems, processes, practices and operations. Improving organisational operations requires that organisations should commit themselves to and undergo changes on a regular and continuous basis in terms of the human and technical aspects. It is for this reason that Wharton Executive Education (2011) declares change as holding the key to organisational development and sustainability. All organisations with visionary and progressive leadership aspire for growth and survival and this aspiration stands at the centre of change taking place on a continuous basis within the modern business organisation, be it profit making-driven or public service delivery-oriented (Imberman, 2009; Kohurt, 2010; Agboola \& Salawu, 2011; Turner, 2011). However, despite frequent and continuous changes taking place in organisations, organisations are not making any progress in terms of achieving their organisational change objectives due to an alarmingly high failure rate in change implementation (Balogun \& Hope Hailey, 2004; Van Tonder, 2004a, 2006; Bregman, 2009). The neglect of the human element, which is regarded as playing a significant role in determining the course of organisational change initiatives in terms of whether they will succeed or not (Armenakis \& Harris, 2009; Panao, 2010), is blamed for the low success rate in change implementation. Organisational change involves various human dynamics which, when not addressed, impact negatively on the change implementation process. These human dynamics of organisational change include people's perceptions and experiences of change and the relationship between perceptions and experiences and the status of change.

According to Van Tonder (2004a), people perceive and experience change events and processes differently, positively or negatively, depending on their willingness and ability to adapt to change, which also come up in different ways. People's perceptions and experiences of the organisation, managers, and their management styles evoke emotional reactions that may lead to people's acceptance of and support for, or rejection of and opposition and resistance to change. It is an established empirical fact that negative perceptions and experiences of change arouse negative emotional reactions that lead to opposition and resistance to change (Van Tonder, 2004a). This view is supported by Stensaker and Meyer (2011) who emphasise that people's perceptions and experiences of change influence their emotional reactions to change. The implications of the foregoing assertions are that negative emotional reactions can hinder the effective implementation of change as a result of opposition and resistance thereto. According to Thomas and Hardy (2011), individual adaptation to change is critical to survival at both individual and organizational levels. Therefore, people's experience of negative emotions implies that people have not adapted to change. Negative attitudes towards change, which emanate from negative perceptions and experiences of change, serve to ignite and fuel people's opposition and resistance to change. For this reason, negative perceptions and experiences of change do serve as a hindrance to effective change implementation. On the other hand, positive perceptions and experiences of change incite positive emotional reactions that lead to the acceptance of, and support for change. They galvanise and mobilise the support for change. They build the required support for change. For this reason, one may argue that positive perceptions and experiences of change do contribute towards effective implementation of organisational change efforts. They stand at the centre of the success of change efforts.

Therefore, it can be argued that effective change implementation depends on amongst other things, a complete awareness and appreciation of how people at personal level perceive and experience change, and how these 
perceptions and experiences relate to the status of (that is, progress with) change, so that managers can intervene with a view to mitigating the impact of negative perceptions and experiences such that they have limited or no negative effect on the status of change (Van Tonder, 2004b). Previous empirical studies have highlighted that transformational change affect people more in a negative than in a positive sense (Van Tonder, 2004a; Worrall and Cooper, 2004). Hence, people react to transformational change more negatively than positively. Without people's concerns about transformational change being addressed, negative perceptions, reactions and experiences will continue to be a threat to the successful implementation of transformational change interventions. Managers need to be mindful of the fact that transformational change efforts are not only driven by people, but they are also experienced by people (Rodda, 2007; Imberman, 2009; Sloyan, 2009). The argument presented above points to a causal relationship between people's perceptions and experiences of change and the status of change, which can be diagrammatically represented as follows:

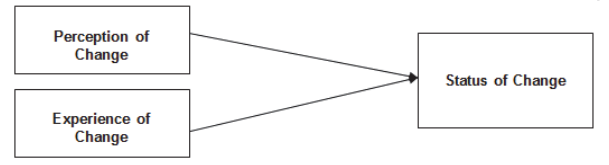

The foregoing theoretical perspectives indicate that both people's perceptions and experiences of change have a simultaneous effect on the status of (i.e. progress with) change in any organisation.

\section{Research Methodology}

This study utilised a two-pronged research approach, which encompassed a literature study and a quantitative empirical study. The study applied three types of research designs, namely the exploratory design, the survey design, and descriptive design. A random, purposive and probability samples of 1000 correctional officials and 500 offenders were utilised, which were drawn from 7593 correctional officials and 13, 520 sentenced offenders, thereby constituting 13.17\% and $8.14 \%$ samples respectively. The procedure followed in the execution of this empirical study incorporated the following process of undertaking a pilot study; distributing and administering survey questionnaires; and scoring and computing the responses. The empirical data was collected by means of two survey questionnaires constructed for both correctional officials and offenders. A 5-point Likert type response scale was utilised in the two questionnaires to measure correctional officials' and offenders' perceptions and experiences of DCS transformational change.

The statistical analysis exercise conducted involved two phases, with phase 1 focusing on descriptive statistics with a view to providing confirmation that the two questionnaires used as measuring instruments were reliable and valid for the purpose of the study; while phase 2 dealt with inferential statistics through the utilisation of the Structural Equation Modelling (SEM) statistical technique, which was employed to measure the existence of causal links between variables. The Kaiser-Meyer-Olkin (KMO), the measure of sampling adequacy (MSA), and the Bartlett's test of sphericity were conducted in order to determine the adequacy and sphericity of the intercorrelation matrix. The reliability of measuring instruments was checked through calculating a reliability coefficient (Cronbach Alpha) by means of a reliability analysis. In terms of response rate the return rate of $71.3 \%$ and the frequency rate of $98.2 \%$ for valid responses were recorded for correctional officials. For the offenders' sample, the return rate of $58.2 \%$ and the frequency rate of 97.6 for valid responses were recorded.

A careful examination of individual items on correctional officials' and offenders' questionnaires points to high face validity. The contents of the questionnaires were found to be relevant to the research questions dealing with correctional officials' and offenders' perceptions and experiences of the DCS transformational change, thereby confirming content validity. From the results of face and content validity, it was concluded that the questionnaires utilised in the study measured what they were designed to measure in terms of perceptions and experiences of change. With regards to reliability analysis, the conducting of suitability of data for factor analysis exercise, which was undertaken through the utilisation of the KMO measure of sampling adequacy and the Barlett's test for sphericity (Kaiser, 1970), points to the fact that the data sets complied with the requirements of sampling adequacy and sphericity and could thus be subjected to factor analysis as the KMO MSA values for the perception and experience of the DCS change variables in respect of correctional officials and offenders were highly significant because they were well above the recommended value of 0.6 (Hair, Anderson, Tatham, \& Black, 2003; Hair, Anderson, Tatham \& Black, 2006; Tabachnick \& Fidell, 2007). The Bartlett's test values, on the other hand, displayed statistical significance $(p=0.000)$ in that the values were below .05 , thereby supporting the factorability of the correlation matrices. Regarding reliability statistics from reliability analysis, the Cronbach alpha coefficients indicated that the measuring instruments had acceptable reliability and consistency in terms of measuring the perceptions and experiences of the DCS change, as well as the causal link between correctional officials' and offenders' perceptions and experiences of the DCS change and the status thereof that they were designed to measure. 


\section{Data Analysis and Discussion of Findings}

\subsection{Relationship between correctional officials' and offenders' perceptions and experiences of the DCS transformational change and the status thereof}

The structural model in respect of the correctional officials, as depicted below in terms of Table 1), attempts to describe the following relationships: 1) the causal links among the three directly measured variables, namely the perception, the experience, and the status of the DCS transformational change; 2 ) the association between the measured variables and their underlying latent factors; and 3 ) the relationships among the latent factors per variable and across variables.

Table 1. Structural Equation Model: Covariance Matrix: Covariance among Exogenous Variables - Correctional Officials

\begin{tabular}{cccccc}
\hline Variables & Covariance Coefficient & p-value & Standard Error & $\mathrm{t}$ - value & Standard Error \\
\hline F4 - F4 F3 - F3 & -.512 & $-5.311 @$ & .096 & $-4.726 @$ & .108 \\
F5 - F5 F3 - F3 & .276 & $5.381 @$ & .051 & $3.871 @$ & .071 \\
F6 - F6 F3 - F3 & -.291 & $-4.963 @$ & .059 & $-4.371 @$ & .059 \\
F5 - F5 F4 - F4 & -.193 & $-3.732 @$ & .052 & $-3.212 @$ & .060 \\
F6 - F6 F4 - F4 & .303 & $4.632 @$ & .066 & $4.325 @$ & .070 \\
F6 - F6 F5 - F5 & -.217 & $-5.632 @$ & .039 & $-4.815 @$ & .045 \\
\hline
\end{tabular}

Note:

1. Variables defined as follows: F3 = Perception and experience of DCS change (Perc-exp); F4 = Perceived nature (type of change) of DCS change (Perc-nat); F5 = Negative affect (Neg-aff); F6 = Positive affect (Pos-aff).

2. Parameter estimates significant at 0.05 if $t$-value $>1.96$.

3. Parameter estimates significant at 0.01 if t-value $>2.56$.

4. Covariances between the latent constructs significant at the 0.01 level (marked with @).

5. $r=0$ : no covariation at all.

6. $0<r<1$ : two variables increase/decrease together.

7. $r=1.0$ : perfect covariation.

8. $-1<r<0$ : one variable increases as the other decreases.

9. $r=-1.0$ : perfect negative/inverse covariation

Source: Authors Fieldwork

A consolidated hypothesised structural model of relationships among the perception, experience and status of the DCS change and the estimated path coefficients of the hypothesised model in respect of correctional officials is shown below.

Figure 1 Consolidated Hypothesised Structural Model of Relationships and Estimated Path Coefficients of the Hypothesised Model - Correctional Officials

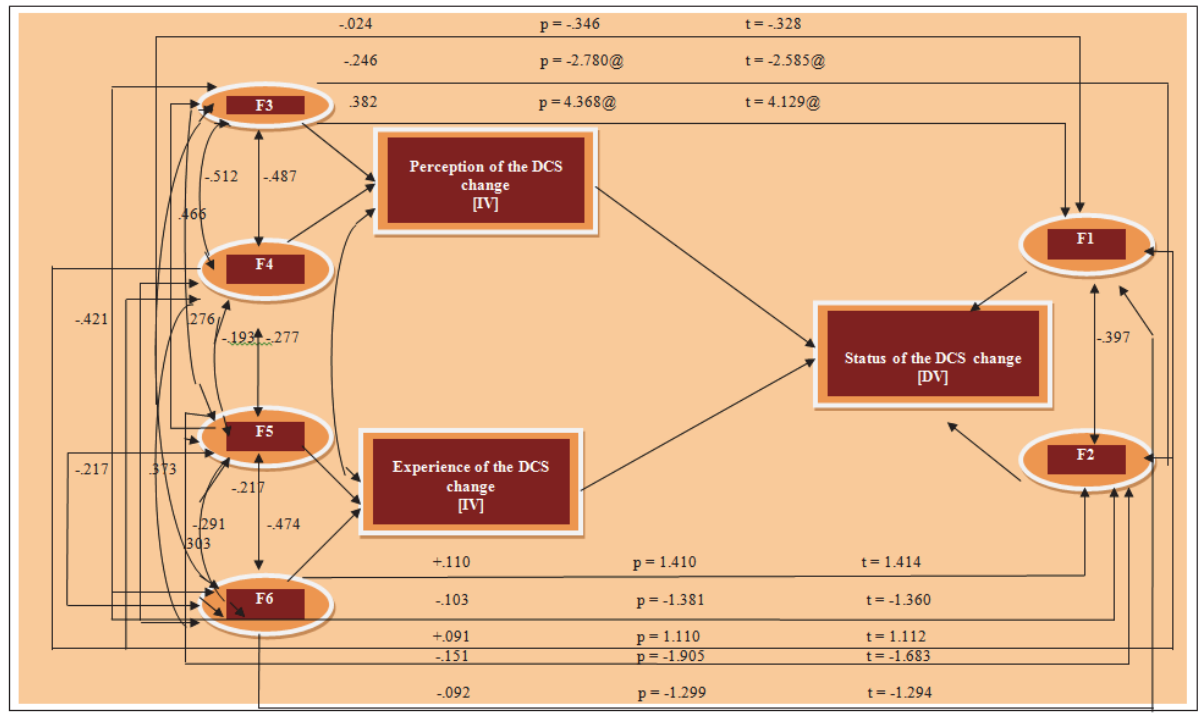

Note: 1. F1 = Perc-eff; F2 = Ori-treat; F3 = Perc-exp; F4 = Perc-nat; F5 = Neg-aff; F6 = Pos-aff.

2. Correlations significant at $t>1.96(p>.05)$ or $t>2.56(p>.01)$ (Harrell, 2001).

3. The higher the correlation, the better the reliability.

4. A correlation of zero means that one variable cannot be predicted from the other without a large error. 
5. A large correlation coefficient is significant.

6. Non-significant correlation means meaningless prediction of one variable from the other

7. Significant correlation below .7: weak relationship with much error of prediction.

8. Significant correlation above .7: strong relationship with moderate error of prediction.

9. Significant correlation above .9: very strong relationship with good accuracy of prediction) (Upton \& Cook, 2006

10. There is a statistically significant relationship if the null hypothesis is rejected

11. Curved double-headed arrows represent covariations among latent variables.

12. Straight double-headed arrows represent correlations among latent variables.

Source: Authors Fieldwork

The structural model displayed above shows the manner in which the latent factors of the perception and experience of the DCS change variables influence changes in the latent factors of the status of the DCS change variable. The influence assumes the following pattern: The perception and experience of the DCS change (F3) is the only latent variable in the structural model that influences both the perceived effectiveness of correctional centres as rehabilitative institutions (F1) and the orientation towards (and treatment of) offenders (F2). Other latent factors underlying exogenous variables do not exert any significant influence on any of the latent factors constituting the status of the DCS change. Second, comparing the influence of both the perception and experience of the DCS change variables on the status of the DCS change, the following emerges: 1) The correlation between the perception of DCS change and the status of DCS change is stronger ($.246, .382,+.091$ and -.103$)$ than the correlation between the experience of DCS change and the status of DCS change ($.151,-.024,+.110$ and -.092 ). It should be remembered that the higher the correlation coefficient, the stronger the relationship; 2) The association between the perception of DCS change and the status of DCS change is more reliable than the association between the experience of DCS change and the status of DCS change. The stronger the relationship, the more reliable it is; 3) The causal link between the perception of DCS change and the status of DCS change is statistically significant; whereas the causal link between the experience of DCS change and the status of DCS change variable is not statistically significant.

From the above empirical findings, one can state the following: 1) The perception of DCS change variable has the most influence on the status of DCS change variable (the larger the coefficient of an independent variable, the larger the influence on the dependent variable); 2) The perception of DCS change variable causes variation in the status of DCS change variable more than the experience of DCS change variable; 3) The status of DCS change can be predicted better and more from the perception of DCS change than from the experience of DCS change; 4) There are significant covariations between the pairs of exogenous latent variables (factors) of one exogenous variable and across the two exogenous variables if one considers that the covariance coefficients are significant at $r>0 ; 5$ ) There are notable relationships between the pairs of exogenous latent variables of one exogenous variable and across the two exogenous variables if one considers that the correlation coefficients are significant at $r>0$; 6) The covariation between the two latent variables of the perception of DCS change is much stronger and reliable (-.512) than the covariation between the two latent variables of the experience of DCS change $(-.219) ; 7)$ The association between the two latent variables of the perception of DCS change is stronger and reliable (-.487) than the association between the two latent variables of the experience of DCS change (-.474).

\subsection{Relatedness of offenders' perceptions and experiences of the DCS change to the status of the DCS change}

The graph showing structural model captured below reflects correlations among unobserved latent factors constituting the two exogenous variables and the one endogenous variable in respect of the offenders. This structural model (in terms of Table 2) aims to explain three types of correlations as follows: 1) The correlations among the three directly measured variables, namely the perception, the experience, and the status of DCS change; 2) The links between the measured variables and their underlying latent factors (indirectly observed variables); 3 ) The associations among the latent factors per variable and across variables.

Table 2. Structural Equation Model: Covariance Matrix: Covariances between Pairs of Exogenous Variables - Offenders

\begin{tabular}{cccccc}
\hline Variables & Covariance Coefficient & p-value & Standard Error & $\mathrm{t}$ - value & Standard Error \\
\hline F2 - F2 F1 - F1 & -.216 & $-4.634 @$ & .047 & $-4.427 @$ & .049 \\
F3 - F3 F1 - F1 & .369 & $5.161 @$ & .072 & $5.183 @$ & .071 \\
F4 - F4 F1 - F1 & .244 & $3.334 @$ & .073 & $3.276 @$ & .075 \\
F5 - F5 F1 - F1 & -.148 & $-2.961 @$ & .050 & $-2.806 @$ & .053 \\
F3 - F3 F2 - F2 & .167 & $2.910 @$ & .057 & $2.712 @$ & .061 \\
F4 - F4 F2 - F2 & -.349 & $-4.268 @$ & .082 & $-4.299 @$ & .081 \\
\hline
\end{tabular}




\begin{tabular}{lccccc}
\hline F5 - F5 F2 - F2 & .161 & $3.113 @$ & .052 & $3.070 @$ & .052 \\
F4 - F4 F3 - F3 & -.189 & $-1.969 @$ & .096 & $-2.107 @$ & .090 \\
F5 - F5 F3 - F3 & .048 & .776 & .062 & .734 & .066 \\
F5 - F5 F4 - F4 & -.505 & $-4.393 @$ & .115 & $-4.275 @$ & .118 \\
\hline
\end{tabular}

Source: Authors Fieldwork

A consolidated hypothesized structural model of relationships among the perception, experience and status of the DCS change and the estimated path coefficients of the hypothesized model in respect of offenders is given below.

Figure 2 Consolidated Hypothesised Structural Model of Relationships and Estimated Path Coefficients of the Hypothesised Model - Offenders

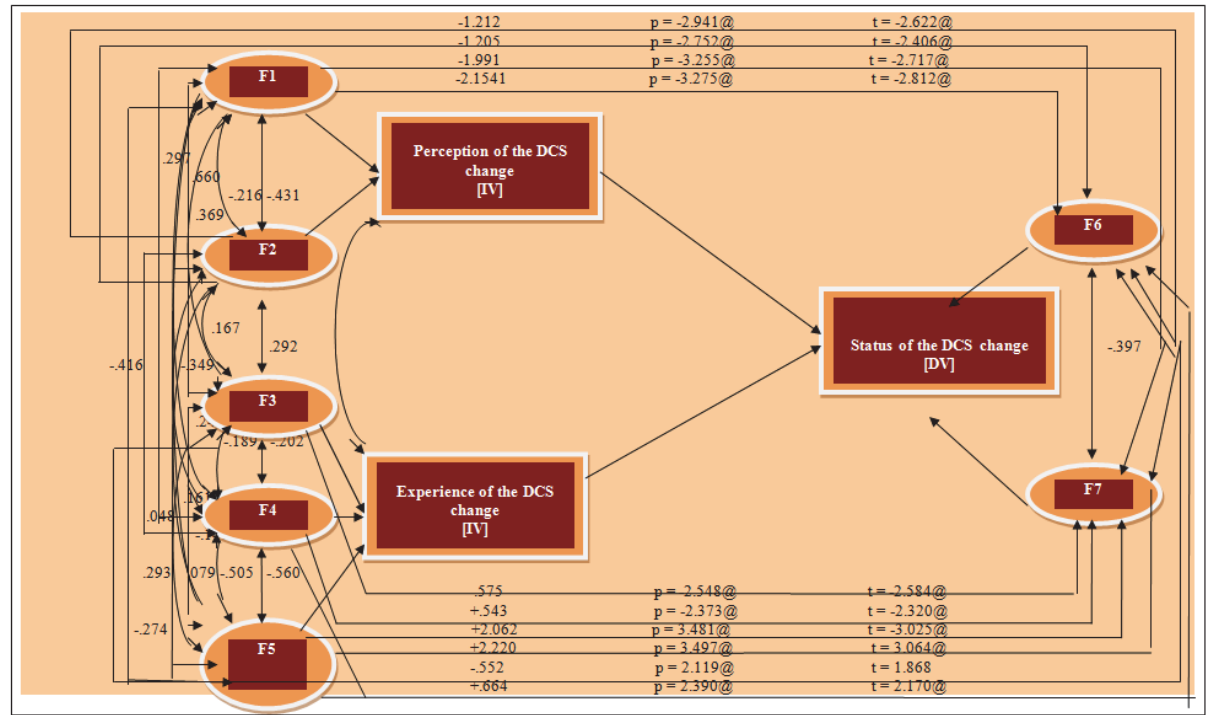

Note: 1. F1 = Neg-aff; F2 = Pos-aff; F3 = Intro-anx-aff; F4 = Perc-exp; F5 = Per c-nat; F6 = Treat-off; F7 = Perc-eff.

2. Correlations significant at $t>1.96(p>05)$ or $(t>2.56(p>.01)$ Harrell, 2001).

The structural model reflected above indicates the manner in which the latent factors of the perception and experience of DCS change variables have effect on the latent factors of the status of DCS change variable. The effect is as follows: 1 ) The negative affect of DCS change (F1) influences both the treatment of offenders (F6) and the perceived effectiveness of correctional centres as rehabilitative institutions/instruments (F7); 2) The positive affect of DCS change (F2) causes changes in both the treatment of offenders (F6) and the perceived effectiveness of correctional centres as rehabilitative institutions/instruments (F7); 3) The introspective-anxious effect of DCS change (F3) exerts influence on both the treatment of offenders (F6) and the perceived effectiveness of correctional centres as rehabilitative institutions/instruments (F7); 4) The perception and experience of DCS change (F4) affect changes on both the treatment of offenders (F6) and the perceived effectiveness of correctional centres as rehabilitative institutions/instruments (F7); and 5) The perceived nature (type of change) of DCS change (F5) has an effect on both the treatment of offenders (F6) and the perceived effectiveness of correctional centres as rehabilitative institutions (F7).

Furthermore, when comparing the influence of both the perception and the experience of DCS change exogenous variable on the status of DCS change variable, the following results came up: 1) The correlation between the experience of DCS change and the status of DCS change is a very high, dependable and much stronger one $(-1.991,-2.154,+2.062$, $+2.220,-1.212$ and -1.205$)$ than the correlation between the perception of DCS change and the status of DCS change ($.552,+.664,+.543$ and -.575$)$. Then higher the correlation coefficient, the stronger the relationship); 2) the association between the experience of DCS change and the status of DCS change is more reliable than the association between the perception of DCS change and the status of DCS change. The stronger the relationship, the more reliable it is; and 3) both the perception and experience of DCS change variables have each a statistically significant relationship with the status of DCS change.

Based on the above findings, the following deductions are made: 1) both the perception and experience of DCS change variables have an influence on the status of DCS change. The larger the coefficient of an independent variable, the larger the influence of the dependent variable; 2) both the perception and experience of DCS change variables cause 
variation on the status of DCS change variable; and 3) the status of DCS change variable can be predicted from both the perception and experience of DCS change variables; 4) there are important covariations between the pairs of exogenous latent variables (factors) of one exogenous variable and across the two exogenous variables when considering that covariance coefficients are significant at $r>0.5$ ) there are meaningful correlations between the pairs of exogenous latent variables (factors) of one exogenous variable and across the two exogenous variables when considering that covariance coefficients are significant at $r>0 ; 6$ ) the covariation between the two latent variables of the perception of DCS change are stronger and reliable $(-.505)$ than the covariation among the three latent variables of the experience of DCS change exogenous (-.216, .167 and .369); 7) The association between the two latent variables of the perception of DCS change $(-.560)$ and the correlations among the three latent variables of the experience of DCS change $(-.431, .292$ and .660$)$ are all moderately stronger and reliable.

\subsection{Comparing and contrasting the relationship patterns of change perception, change experience and change status} obtained for correctional officials and offenders

The empirical evidence portrayed herein, gathered from correctional officials and offenders, points to the fact that there is relatedness of perceptions and experiences of change to the status of change. No matter how small or big, low or high, and weak or strong, but empirical findings reveal that there is a relationship between people's perceptions and experiences of change on one hand, and the status of change on the other.

\subsection{Comparing and contrasting relationships between DCS change perceptions and experiences and DCS change status from the perspective of correctional officials and offenders}

The highlighted issues have emanated when comparing and contrasting relationships between the perception and experience of DCS change and the status of DCS change from the perspectives of correctional officials and offenders. Firstly offenders perceive a much stronger relationship between the perception of DCS change and the status of DCS change than correctional officials' perception of the same relationship. This is evidenced by the correlation coefficients that are higher or larger in the case of offenders $(-.552,+.664,+.543$ and -.575$)$, compared to the lower or smaller correlation coefficients for correctional officials $(-.246, .382,+.091$ and -.103$)$. Therefore, given the larger coefficients (for offenders) and smaller coefficients (for correctional officials), it can be maintained that offenders perceive a much stronger correlation between the perception of DCS change and the status of DCS change than correctional officials' perceived weaker correlation between the perception of DCS change and the status of DCS change. This is in line with the claim that the larger the correlation coefficients, the stronger the correlation; the lower the coefficient, the smaller or weaker the correlation (Guilford in Tredoux \& Durrheim, 2002; Saurina \& Coenders, 2002; Gall, Gall \& Borg, 2003; Upton $\&$ Cook, 2006). Thus, considering the claim that the stronger the correlation, the more reliable the correlation becomes, it can be stated that the association perceived by offenders between the perception of DCS change and the status of DCS change is more reliable than the association between the two said variables as perceived by correctional officials. Additionally, both offenders and correctional officials perceived a statistically significant correlation between the perception of DCS change and the experience of DCS change. The only exception is with regards to the correlation between the perceived nature of the change factor of the perception of DCS change and the two latent factors [perceived effectiveness of correctional centres as rehabilitative institutions, and orientation towards and treatment of offenders] of the status of DCS change. In this case, the correlation has been found to be statistically insignificant. For the offenders, all the correlations between the pairs of latent variables have been found to be statistically significant, thereby rendering the correlation between the perception of DCS change and the status of DCS change statistically significant.

Also from the above, it can be inferred that the perception of DCS change (IV) has the most influence on the status of DCS change (DV) from the perspective of offenders. From the side of correctional officials, the perception of DCS change variable has less influence on the status of DCS change when comparing this with findings from offenders' perspective. Hence, offenders perceive a much stronger correlation between the experience of DCS change and the status of DCS change than correctional officials' perception of the same correlation. This is evidenced by the correlation coefficients that are higher or larger from the side of the offenders $(-1.991,-2.154,+2.062,+2.220,-1.212$ and -1.205$)$ ), compared to the lower or smaller correlation coefficients for correctional officials $(-.151,-.024,+.110$ and -.092$)$. Therefore, given the larger coefficients (for offenders) and smaller coefficients (for correctional officials), it can be concluded that offenders perceive a much stronger association between the experience of DCS change and the status of DCS change than correctional officials' perceived weaker association between the experience of DCS change and the status of DCS change. This is in line with the assertion by Guilford (cited in Tredoux \& Durrheim (2002), Saurina \& Coenders (2002), Gall, Gall and Borg (2003) and Upton and Cook (2006) that the larger the correlation coefficients, the 
stronger the association; and the lower the coefficient, the smaller or weaker the association. Thus, the relationship perceived by offenders between the experience of DCS change and the status of DCS change is more reliable than the relationship between the two said variables as perceived by correctional officials. More than that, offenders' perceived correlation between the experience of DCS change and the status of DCS change as statistically significant compared to the same correlation perceived by correctional officials, which has been found not to be statistically significant. For the offenders, all the correlations between the pairs of latent variables have been found to be statistically significant, thereby rendering the correlation between the experience of DCS change and the status of the DCS change statistically significant. But for correctional officials, all the correlations between the independent variable' latent factors and the dependent variable's latent factors were found to be statistically insignificant, thereby rendering the correlation between the experience of DCS change (IV) and the status of DCS change (DV) statistically insignificant. Based on the findings, it can be deduced that the experience of DCS change has the most influence on the status of DCS change from the perspective of offenders. From the side of correctional officials, the experience of DCS change has less influence on the status of DCS change when compared to empirical findings from offenders' perspectives. Finally, the experience of DCS change, compared to the perception of DCS change, has the most effect on the status of DCS change. This becomes obvious when a comparison of correlation coefficients (standardised values) and statistical significance values (unstandardised coefficients) of both the perception of DCS change and the experience of DCS change is made.

\section{Implications for Organisations}

The empirical findings regarding the relatedness of correctional officials' and offenders' perceptions and experiences of the DCS transformational change to the status thereof have certain implications. Firstly, the findings emphasise the importance of managing both people issues and technical aspects insofar as the change management process is concerned. This is so because the findings on the relationship between correctional officials' and offenders' perceptions and experiences of DCS change and the status of (that is, progress with) the DCS change have highlighted the significant role that the human factor plays in the management of change. This means that without due recognition being given to the human element, success in change implementation will remain a pie-dream The second implication is that it is people's perceptions and experiences of change influence progress with change. This means that managers should manage people's perceptions and experiences through decisive managerial intervention. Managers who take decisive action to mitigate people's perceptions and experiences effectively do so for the good of their organisations in terms of ensuring the success of change efforts. On the other hand, managers who ignore people's perceptions and experiences of change do so at their own peril. The third implication relates to the impact of change. What this suggests is that for managers to ensure effective facilitation of change implementation, they need to mitigate the negative impact of change at personal level.

Hence, differences in terms of progress between the effectiveness of correctional centres as institutions of rehabilitation and the treatment of offenders suggest that there will not be any much headway in terms of transforming correctional centres into effective rehabilitative institutions unless there is improvement in the treatment of offenders by correctional officials. The treatment of offenders can only improve when the mindsets of correctional officials in terms of their perceptions of, and attitudes towards DCS change are changed through personal transformation interventions. Negative mindsets have given rise to negative perceptions and attitudes, thereby impacting negatively on the treatment of offenders. This calls for managerial intervention. The findings therefore, imply that people within organisations are the main source of organisational change failures, which in turn makes people an organisational change risk (Allen, Jimmieson, Bordia \& Irmer, 2007). In that case, individual change has to serve as a precursor to organisational change. Thus, the success of organisational change depends largely on people changing not only their behaviours, attitudes and beliefs, which unfortunately impact on their perceptions and experiences of change, as well as their emotional reactions to the change, which would minimise and contain opposition and resistance to change, thereby ensuring the effective facilitation of change efforts.

\section{Conclusion}

The empirical findings highlighted in this paper point to the fact that the success of transformational change at organisational level (organisational transformation) hinges on successful transformational change at individual level (personal transformation), particularly when it comes to mitigating negative perceptions and experiences of change, so that they do not have a negative impact on progress with change. The fact that change is perceived and experienced by people individually and collectively shows that change is rooted in human dynamics (individual and group dynamics) rather than organisational dynamics. Therefore, the transformation of the individual through changing people's negative 
perceptions and experiences for the better as well as reinforcing positive perceptions and experiences becomes critical for the effective implementation of transformational change efforts. The transformation of people's mindsets and attitudes, which inform their perceptions of change which, in turn influence their emotional reactions to change, as well as their experiences of change, becomes critical if managers are to turn around the unfortunate situation of the high failure rate in change implementation.

\section{References}

Agboola, A.A. \& Salawu, R.O. (2011). Managing deviant behaviour and resistance to change. International Journal of Business and Management, 6(1):235242.

Allen, J., Jimmieson, N.L., Bordia, P., \& Immer, B.E. (2007). Uncertainty during organisational change: Managing perceptions through communication. Journal of Change Management, 7(2):187-190

Alvesson, M. \& Svenningsson, S. (2008). Forundringnarbete I organisationer, Libes. Retrieved from: http://www.google.com on 16 July 2011.

Armenakis, A. \& Harris, S. (2009). Reflections: Our journey in organizational change research and practice. Journal of Change Management, 9 (2):127-142.

Balogun, J. \& Hope Hailey, V. (2004). Exploring strategic change. London: Prentice Hall.

Bregman, P. (2009). How to counter resistance to change. Harvard Business Press. Retrieved from: http://blogs.hbr/2009/04/how-to-counter-resistance-to-c/ on 08 August 2012.

Burnes, B. (2004). Managing change: A strategic approach to organisational dynamics. Harlow: Prentice Hall.

Choi, M., \& Ruona, W. (2011). Individual readiness for organizational change and its implications for human resource and organization development. Human Resource Development Review, 10 (1): 46-73.

Coetzee, C.J.H. \& Stanz, K.J. (2007). "Barriers-to-change" in a governmental service delivery type organisation. SA Journal of Industrial Psychology, 33 (2):76-82

Decker, D., Wheeler, G.E., Johnson, J., \& Parsons, R.J. (2001). Effect of organisational change on the individual employee. The Health Care Manager, 19(4): 1-4.

Department of Correctional Services. (2005). White Paper on Corrections in South Africa. Pretoria: Government Printers.

Gall, M.D., Gall, J.P. \& Borg, W.R. (2003). Educational research: An introduction. (7th ed). Boston: Allyn \& Bacon.

George, J.M. and Jones, G.R. (2001). Towards a process model of individual change in organizations, Human Relations, 54(4):419-444.

Hair, J. F., Anderson, R. E., Tatham, R.L. \& Black, W. C. (2003). Multivariate Data Analysis. India: Pearson Education.

Hair, J.F., Anderson, R.E., Tatham, R.L. \& Black, W.C. (2006). Multivariate data analysis. Upper Saddle River, NJ: Prentice-Hall.

Imberman, M.D. (2009). Organizational change and organizational justice: Assessing the impact on organizational commitment, change-oriented, organizational citizenship behaviour and attitude toward future change. PhD Dissertation. ProQuest Dissertations and Theses, 2011/09/08, Alliant International University, Los Angeles, California.

Kaiser, H.F. (1970). A second generation Little Jiffy. Psychometrika, 35:401-415.

Kohurt, A.M. (2010). Significant workplace change: Perspectives of survivors. D.Ed Dissertation. Northern Illinois University, Dekalb, Illinois.

Lotich, P. (2011). Why do organizational change efforts often fail? Thriving Small Business. Retrieved from http://www.project-managementcom.info/douglas-mcgregor-human-side-of-enterprise/ on 23 September 2011.

Macri, D.M., Tagliaventi, M.R., \& Bertolotti, F. (2002). A grounded theory for resistance to change in a small organization. Journal of Organizational Change Management, 15(3):292-310.

Panao, A. (2010). Mastering the deadly art of change. The Japan HR Society. Retrieved from: http://www.japanic.com/japan-inc-blog on 16 June 2012.

Refferty, A.E. \& Griffin, M.A. (2006). Perceptions of organisational change: A stress and coping perspective. Journal of Applied Psychology, September, 91(5):1154-1160

Rodda, J. (2007). A multilevel examination of employee reactions to organizational change. PhD Dissertation. DePaul University, Chicago.

Saurina, C. \& Coenders, G. (2002). Predicting overall service quality. A structural equation modelling approach. Developments in Social Science Methodology, 18:217-238.

Sloyan, R.M. (2009). Trust, sensemaking and individual responses to organizational change. Doctoral Dissertation at Benedictine University.

Stensaker, I.G. \& Meyer, C.B. (2011). Change experience and employee reactions: developing capabilities for change. Personnel Review, 41(1):106-124.

Tabachnick, B. \& Fidell, L. (2007). Using multivariate statistics. Boston: Allyn \& Bacon.

Thomas, R. \& Hardy, C. (2011). Reframing resistance to organizational change. Scandinavian Journal of Management, 27:322-331.

Tredoux, C.G. \& Durrheim, K.W (2002). Numbers, hypotheses and conclusions. Cape Town: Juta.

Turner, D. (2011). The paradox of change management. Winnipeg, MB: Turner Change Management Inc.

Turner, D-M., Hallencreutz, J. \& Haley, H. (2009). Leveraging the value of an organizational change management methodology. The International Journal of Knowledge, Culture and Change Management, 9(9): 1-34.

Upton, G. \& Cook, I (2006). Oxford dictionary of statistics. Oxford University Press. Retrieved from http:/len.wikipedia.org/wiki/Association(Statistics) on $2011 / 04 / 05$.

Ursiny, T. \& Kay, B.A. (2007). The top performer' guide to change. Napierville: Sourcebooks, Inc.

Vakola, M. \& Nikolaou, I. (2005). Attitudes towards organisational change. What is the role of employees' stress and commitment? Employee Relations, 27(2): 160-174.

Van Tonder, C.L. (2004a). Organisational change: Theory and practice. Pretoria: Van Schaik.

Van Tonder, C.L. (2004b). Organisational Development - Purposefully engaging change, Part I. Management Today, 20(10): 51-57.

Van Tonder, C.L. (2006). Change risk and ignorance: Attempting to cross chasms in small steps. SA Journal of Human Resource Management, 4 (3): 1-11.

Van Tonder, C.L. (2009). Organization identity as managerial concern. In N. Delener, L. Fuxman, F. Victor Lu, A. Putnova \& L.E. Rivera-Solis (Eds.), Readings book: Eleventh International Conference of the Global Business and Technology Association(GBATA), 1171-1177.

Walston, S.L. \& Chadwick, C. (2003). Perceptions and misperceptions of major organisational changes in hospitals: Do change efforts fail because of inconsistent organisational perceptions of restructuring and reengineering? International Journal of Public Administration, 26(14),:1581-1585.

Wharton Executive Education. (2011). Harnessing fire: Managing emotions for successful organizational change. Wharton@work. E-Newsletter for the Aresty Institute of Executive Education.

Worrall, L. \& Cooper, C.L. (2004). Managers, hierarchies and attitudes: A study of UK managers. Journal of Management Psychology, 19(1): 41-68.

Zolno, S. (2010). Personal change management. Retrieved from: http://www.proactiona(2010)sociates.com on 28 June 2012. 